\title{
Phase I trial outcomes in older patients with advanced solid tumours
}

\author{
K H Khan ${ }^{1,2}$, T A Yap ${ }^{1,3}$, A Ring ${ }^{4}$, L R Molife ${ }^{1}$, S Bodla ${ }^{1}$, K Thomas ${ }^{1}$, A Zivi ${ }^{1}$, A Smith ${ }^{1}$, I Judson ${ }^{1}$, U Banerji ${ }^{1,3}$, \\ J S de Bono ${ }^{1,3}$ and S B Kaye ${ }^{\star, 1,3}$ \\ ${ }^{1}$ Drug Development Unit, The Royal Marsden NHS Foundation Trust, Sutton SM2 5PT, UK; ${ }^{2}$ Gastrointestinal Cancers Unit, \\ The Royal Marsden NHS Foundation Trust, Sutton SM2 5PT, UK; ${ }^{3}$ Division of Clinical Studies, The Institute of Cancer Research, \\ Sutton SM2 5NG, UK and ${ }^{4}$ Breast Unit, The Royal Marsden NHS Foundation Trust, Sutton SM2 5PT, UK
}

Background: This study had two aims: (a) to test the hypothesis that advanced age is associated with lower levels of tolerability and clinical benefit to experimental Phase I trial agents; (b) to assess the validity of the Royal Marsden Hospital (RMH) prognostic score as a patient selection tool in older patients.

Methods: Clinico-pathological characteristics and treatment outcomes of all patients treated consecutively from 2005 to 2009 in phase I trials at the RMH were recorded. All toxicity and clinical outcome data were compared between patients aged below and above 65 years of age.

Results: One thousand and four patients were treated in 30 Phase I trials, with 315 (31\%) patients aged 65 years and older. Grade $3-5$ toxicities $(22.8 \%$ vs $24.8 \%(P=0.52)$ ), trial discontinuation (6\% vs 4\%; $P=0.33)$, and dose interruptions $(8.0 \%$ vs $8.0 \%(P=0.96))$ were observed at similar rates in patients below and above 65 years of age, respectively. The overall response rate $5.2 \%$ vs $4.1 \%$, progression-free survival (PFS) 1.9 vs 3.5 months and clinical benefit rate (CBR) at 6 months $15.2 \%$ vs $14.3 \%$ were comparable in both groups. To avoid bias due to the potential therapeutic benefit of abiraterone, comparisons were repeated excluding prostate cancer patients with similar results (ORR 4.6\% vs 4\%, PFS 1.8 vs 3.0 months, CBR at 6 months 13.5\% vs $9.5 \%$ ). Multivariate analysis indicated that the previously identified $\mathrm{RMH}$ score (including albumin and lactate dehydrogenase levels) was an accurate predictor of outcome.

Conclusions: Phase I clinical trials should be considered in patients with advanced cancers regardless of age, as older patients who enter these have similar safety and efficacy outcomes as their younger counterparts. The RMH prognostic score can assist in the selection of suitable older patients.

Owing to an ageing population and increasing life expectancy, the frequency and prevalence of older patients ( $\geqslant 65$ years) diagnosed with cancer has risen (Paik et al, 2010; Jemal et al, 2011). Such patients now represent $\sim 60 \%$ of the western world's cancer population and account for $80 \%$ of cancer-related mortality in the United States and Europe. The projected percentage of the US population $\geqslant 65$ years is anticipated to rise further by $20 \%$ by 2030 , and will represent $70 \%$ of patients diagnosed with cancer (Edwards et al, 2002). Specific issues regarding cancer management in elderly patients are therefore an area of increasing concern.
Despite the relatively high frequency of cancer in this patient population, the representation of elderly patients in clinical trials remains relatively poor (Scher and Hurria, 2012). Several studies have investigated the accrual rates of elderly patients in clinical trials. A study conducted by the Southwest Oncology Group (SWOG) involving over 16000 patients enrolled consecutively in clinical trials between 1993 and 1996 showed that 25\% of patients enrolled on to SWOG clinical trials were above the age of 65 years, when compared with $63 \%$ in the US population with cancer $(P<0.001)$ (Hutchins et al, 1999). Similarly, another US-based

*Correspondence: Professor SB Kaye; E-mail: Stan.Kaye@rmh.nhs.uk

Received 9 November 2015; revised 10 December 2015; accepted 14 December 2015; published online 12 January 2016

(c) 2016 Cancer Research UK. All rights reserved 0007-0920/16 
study showed that the proportion of patients aged $\geqslant 65$ years enrolled in clinical trials was $36 \%$, compared with $60 \%$ of the overall US cancer population $(P<0.001)$ (Talarico et al, 2004). A Canadian study examining data from 4174 patients enrolled onto 69 clinical trials between 1993 and 1996, mirrored similar results demonstrating that clinical trials conducted by the National Institute of Canada (NCIC) only enrolled $22 \%$ of patients aged above 65 years compared with 58\% in corresponding Canadian cancer population $(P \leqslant 0.0001)$, indicating that age remained an important barrier in terms of recruitment onto clinical trials (Yee et al, 2003). These findings imply that the extrapolation of trial results from younger to older patients is often necessary, making clinical trial outcomes potentially less meaningful for the older population.

The common challenges specific to older patients with cancer include age-related declines in organ function, altered pharmacokinetics, associated co-morbidities, polypharmacy, and physician perceptions with regard to the tolerability of systemic therapy in treating older patients (Pal et al, 2010).

A study evaluating the attitudes of older patients towards clinical trials concluded that most were willing to consider participation into clinical trials; however, physician barriers and the lack of availability of trials were found to be the most important factors hampering accrual of older cancer patients into clinical trials (Townsley et al, 2006). This is despite the well-recognised observation that large numbers of individuals reach geriatric age without a measurable loss of functional capacity and/or severe co-morbidities (Rubenstein et al, 1986). Such patients should therefore be considered and offered cancer treatments as for younger patients.

Patients with advanced cancers are frequently referred for consideration of Phase I experimental drug trials after the development of disease progression on conventional treatments. However, there is a current scarcity of published data to guide recommendations and policy regarding the referral of patients for consideration of such clinical trials in the elderly population. We therefore conducted a retrospective analysis of all patients with advanced and relapsed malignancies treated on Phase I clinical trials in the Drug Development Unit (DDU) at the Royal Marsden Hospital (RMH), focussing on outcome and prognostic variables of all the patients referred to our phase I unit with a view to define if age was predictive of patient outcomes either with regard to tolerability or efficacy. The primary aim of this study was to test the hypothesis that older patients have lower levels of tolerability and clinical benefit compared with younger patients. We also analysed the frequency of grade $(G) 3$ or G4 toxicities and rates of treatment-related trial discontinuation in these patients, along with standard efficacy parameters. Finally, we explored baseline patient characteristics that were prognostic of progression-free survival (PFS) and overall survival (OS) in all patients, in order to assess the validity of the previously published RMH prognostic score in older patients (Arkenau et al, 2009).

\section{PATIENTS AND METHODS}

This retrospective study included all patients with advanced solid tumours treated consecutively in Phase I clinical trials at the DDU, RMH, UK, from January 2005 to December 2009. Only patients who received at least one dose of an experimental drug were included in this study. Clinical parameters collected included histological subtype, age, gender, Eastern Cooperative Oncology Group (ECOG) performance status (PS), full blood count, biochemical profiles (including alkaline phosphatase), bilirubin, lactate dehydrogenase, (LDH) and albumin), number of metastatic sites, number of previous lines of systemic therapies, distance from home to treatment facility, and details of co-morbidities. Details on severity of co-morbidity was not available although most patients were expected to have well-controlled co-morbidities as part of inclusion criteria into individual phase I studies. All patients were divided into two groups; $<65$ (group A) and $\geqslant 65$ (group B). All study patients had provided written informed consent for participation in the relevant Phase I trials, which were all approved by UK regulatory and independent ethics committees. Approval for this study was obtained from the Institutional Clinical Audit Committee.

Patient follow-up and response evaluation. In all phase I studies, baseline tumour measurements were performed within 4 weeks prior to commencement of treatment. Tumour measurements were repeated every 6-8 weeks during the first 6 months on trial using Response Evaluation Criteria In Solid Tumours (RECIST) version 1.0. Toxicity data were collected from electronic patient records (EPR), and when required, from clinical trial case report forms (CRFs). In all trials included in the present analysis, toxicity was graded according to the Common Terminology Criteria for Adverse Events version 3.0. Overall survival data were obtained from EPR, and when necessary, by contacting the general practitioner or referring institution.

OS was defined as the interval between Cycle 1 Day 1 of a Phase I trial and either the date of death or censored at the date of last follow-up (if death was not observed during the follow-up period). For evaluable patients, PFS was defined as the time elapsed between Cycle 1 Day 1 on study until radiological progression and disease-related death (whichever occurred first); if no evidence of progression was documented at the last follow-up, PFS was censored at the time of last radiological evaluation. Clinical benefit rate (CBR) was defined as complete response $(\mathrm{CR})+$ partial response $(\mathrm{PR})+$ stable disease $(\mathrm{SD})$ for at least 6 months.

Statistical methods. Categorisation of numeric variables was undertaken based on considerations of the standard reference values (normal range vs low/elevated) or according to median values. Variables were compared between groups A and B using a two-sided $\chi^{2}$-test, with $P$-values $<0.05$ considered as significant. Estimates of median PFS and OS (and 95\% confidence interval (CI)) were determined using the Kaplan-Meier method, and OS curves were compared using the log-rank test for categorical variables. Cox regression analysis was undertaken to identify baseline characteristics that provided independent prognostic information. In the multivariate model, a forward stepwise approach was taken. In the univariate analysis, a $P$-value of 0.10 was adopted as the limit for inclusion in the multivariate analysis; in the latter, $P$-values $<0.05$ were considered significant. The $\mathrm{RMH}$ prognostic score ranges from 0 to 3 and is calculated by adding 1 for each variables including: $\mathrm{LDH}>192 \mathrm{Ul}^{-1}$; albumin $<35$ and sites of metastasis $>2$. Expected hazard ratio (HR) for OS in patients with RMH score of $2-3$ vs $0-1$ is 1.4 (95\% CI 1.02-1.88) based on previous publication. A table showing univariate analysis of OS and PFS in the older patient group for RMH score, PS, ALT (by quartiles), creatinine (by quartiles), number of co-morbidities, presence of diabetes, hypertension, age, and number of previous lines of chemotherapy was generated. The first trial entry for each patient only was only considered for this analysis.

\section{RESULTS}

Patient and tumour characteristics. One thousand and four patients were treated between 2005 and 2009 in 30 Phase I clinical trials at the DDU in the RMH (Table 1). Three hundred and fifteen (31\%) patients were $\geqslant 65$ years, whereas the remaining 689 (69\%) were younger than 65 years of age. This included 566 and 250 distinct patients in groups $\mathrm{A}$ and $\mathrm{B}$, respectively. The median age at Phase I trial entry in group B was 69 years (range 65-85) 
Table 1. Patient and tumour characteristics

\begin{tabular}{|c|c|c|c|}
\hline & $\begin{array}{c}\text { Group } A<65 \text { years } \\
n(\%)\end{array}$ & $\begin{array}{c}\text { Group B }>65 \text { years } \\
n(\%)\end{array}$ & $P$-value \\
\hline \multicolumn{4}{|l|}{ Age } \\
\hline $\begin{array}{l}\text { Median } \\
\text { IQR (interquartile range) } \\
\text { Min-Max }\end{array}$ & $\begin{array}{c}52 \\
46-60 \\
16-64\end{array}$ & $\begin{array}{c}69 \\
66-72 \\
65-85\end{array}$ & $\mathrm{~N} / \mathrm{A}$ \\
\hline \multicolumn{4}{|l|}{ Sex } \\
\hline $\begin{array}{l}\text { Male } \\
\text { Female }\end{array}$ & $\begin{array}{l}325(47) \\
364(53)\end{array}$ & $\begin{array}{r}230(73) \\
85(27)\end{array}$ & N/A \\
\hline $\begin{array}{l}0 \\
1 \\
2\end{array}$ & $\begin{array}{c}202(29.3) \\
447(64.9) \\
40(5.8)\end{array}$ & $\begin{array}{r}87(28) \\
211(67) \\
17(5)\end{array}$ & N/A \\
\hline \multicolumn{4}{|l|}{ Co-morbidities } \\
\hline $\begin{array}{l}\text { No } \\
\text { Yes } \\
1 \\
2 \\
3 \\
4 \\
5 \\
\text { Not recorded } \\
\text { Total }\end{array}$ & $\begin{array}{c}425(71.7) \\
168(28.3) \\
168(64.1) \\
75(28.6) \\
12(4.5) \\
2(0.7) \\
1(0.3) \\
4(1.5) \\
262\end{array}$ & $\begin{array}{c}113(49.6) \\
115(50.4) \\
115(56.9) \\
63(31.1) \\
18(7.9) \\
4(2.0) \\
0(0) \\
2(0.1) \\
202\end{array}$ & $<0.001$ ( $>2$ co-morbidities) \\
\hline \multicolumn{4}{|l|}{ Hypertension } \\
\hline $\begin{array}{l}\text { No } \\
\text { Yes }\end{array}$ & $\begin{array}{r}610(88.5) \\
79(11.5)\end{array}$ & $\begin{array}{r}221(70.1) \\
94(29.9)\end{array}$ & $<0.001$ \\
\hline \multicolumn{4}{|l|}{ Diabetes mellitus } \\
\hline $\begin{array}{l}\text { No } \\
\text { Yes }\end{array}$ & $\begin{array}{l}662(96.0) \\
27(4.0)\end{array}$ & $\begin{array}{r}282(89.5) \\
33(10.5)\end{array}$ & $<0.001$ \\
\hline \multicolumn{4}{|c|}{ Vascular disease (angina pectoris, infarct, stroke) } \\
\hline 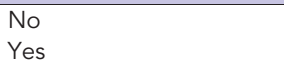 & $\begin{array}{l}650(94.3) \\
39(5.7)\end{array}$ & $\begin{array}{r}283(89.9) \\
32(10.2)\end{array}$ & 0.01 \\
\hline $\begin{array}{l}0 \\
1 \\
2 \\
3 \\
4 \\
>5\end{array}$ & $\begin{array}{c}106(15.3) \\
173(25.1) \\
180(26.1) \\
125(18.1) \\
61(6.9) \\
44(6.3)\end{array}$ & $\begin{array}{l}71(22.6) \\
82(26.0) \\
76(24.1) \\
53(16.9) \\
17(5.4) \\
16(5.1)\end{array}$ & 0.042 \\
\hline \multicolumn{4}{|c|}{ Number of metastatic sites } \\
\hline $\begin{array}{l}0 \\
1 \\
2 \\
3 \\
4 \\
>5\end{array}$ & $\begin{array}{c}21(3.0) \\
156(22.7) \\
240(34.8) \\
164(23.8) \\
79(11.5) \\
29(4.2)\end{array}$ & $\begin{aligned} 5 & (1.6) \\
97 & (30.8) \\
113 & (35.9) \\
71 & (22.6) \\
22 & (7.0) \\
7 & (2.2)\end{aligned}$ & 0.013 \\
\hline \multicolumn{4}{|l|}{ Metastasis to liver } \\
\hline $\begin{array}{l}\text { No } \\
\text { Yes }\end{array}$ & $\begin{array}{l}401(58.2) \\
288(41.8)\end{array}$ & $\begin{array}{l}185(58.8) \\
130(41.3)\end{array}$ & 0.87 \\
\hline \multicolumn{4}{|l|}{ Metastasis to lung } \\
\hline $\begin{array}{l}\text { No } \\
\text { Yes }\end{array}$ & $\begin{array}{l}333(48.3) \\
356(51.7)\end{array}$ & $\begin{array}{l}177(56.2) \\
138(43.8)\end{array}$ & 0.02 \\
\hline \multicolumn{4}{|l|}{ Metastasis to bones } \\
\hline $\begin{array}{l}\text { No } \\
\text { Yes }\end{array}$ & $\begin{array}{l}548(79.5) \\
141(20.5)\end{array}$ & $\begin{array}{l}213(67.6) \\
102(32.38)\end{array}$ & $<0.001$ \\
\hline \multicolumn{4}{|c|}{ Metastasis to lymph nodes } \\
\hline $\begin{array}{l}\text { No } \\
\text { Yes }\end{array}$ & $\begin{array}{l}302(43.8) \\
387(56.2)\end{array}$ & $\begin{array}{l}156(49.5) \\
159(50.5)\end{array}$ & 0.093 \\
\hline
\end{tabular}




\begin{tabular}{|c|c|c|c|}
\hline & $\begin{array}{c}\text { Group } A<65 \text { years } \\
n(\%)\end{array}$ & $\begin{array}{c}\text { Group B }>65 \text { years } \\
n(\%)\end{array}$ & $P$-value \\
\hline \multicolumn{4}{|l|}{ Tumour types } \\
\hline $\begin{array}{l}\text { Gynaecological } \\
\text { Genito-urinary } \\
\text { (prostate) } \\
\text { Upper gastrointestinal } \\
\text { Thoracic } \\
\text { Lower gastrointestinal } \\
\text { Breast } \\
\text { Skin } \\
\text { Connective tissue and brain } \\
\text { Head and neck } \\
\text { Endocrine } \\
\text { Others }\end{array}$ & $\begin{array}{c}138(20.0) \\
92(13.4) \\
49(7.1) \\
104(15.1) \\
59(8.6) \\
62(9.0) \\
53(7.7) \\
52(7.5) \\
42(6.1) \\
14(2.0) \\
23(3.3) \\
50(7.2)\end{array}$ & $\begin{array}{l}31(9.8) \\
93(29.5) \\
83(26.3) \\
40(12.7) \\
38(12.1) \\
60(19.4) \\
10(3.2) \\
26(8.3) \\
5(1.5) \\
6(1.9) \\
0(0) \\
6(1.9)\end{array}$ & N/A \\
\hline \multicolumn{4}{|l|}{ Type of agents } \\
\hline $\begin{array}{l}\text { Anti-angiogeneics } \\
\text { Cell cycle and apoptosis inhibitors } \\
\text { Chromatin remodelling, DNA repair and anti-sense } \\
\text { Cytoplasmic signalling protein inhibitors } \\
\text { Growth factor receptor-targeting agents } \\
\text { Growth factor receptor combined with anti-angiogenesis agents } \\
\text { Oncolytic virus } \\
\text { 5-hydroxylase inhibitors } \\
\text { Protein folding and degradation agents } \\
\text { Cytotoxic combinations }\end{array}$ & $\begin{array}{c}27(3.9) \\
43(6.2) \\
180(26.1) \\
111(16.1) \\
163(23.6) \\
25(3.6) \\
31(4.5) \\
23(3.3) \\
21(3.0) \\
65(9.4)\end{array}$ & $\begin{aligned} & 12(3.8) \\
& 10(3.2) \\
& 69(21.9) \\
& 81(5.7) \\
& 27(8.6) \\
& 53(16.8) \\
& 2(0.6) \\
& 26(8.3) \\
& 8(2.5) \\
& 27(8.5)\end{aligned}$ & \\
\hline
\end{tabular}

comprising $73 \%$ males. In group A, median age was 52 years (range 12-64), which included $47 \%$ males.

As expected, patients who were $\geqslant 65$ had a greater number of co-morbidities compared with the younger patients. These coexisting medical conditions included hypertension, diabetes mellitus, and vascular disease. There were, however, no differences in the frequency of lung disease, such as chronic obstructive pulmonary disease and asthma, or renal disease.

The number of lines of previous chemotherapy treatments received was comparable between both groups of patients (Table 1). Both groups of patients with advanced cancers were heavily pre-treated with prior chemotherapies. Patients in group A had a greater number of metastatic disease sites compared with those in group B. Although there were significantly greater numbers of patients with metastatic spread to lung and lymph nodes, there was no difference in frequency between both groups in metastases to liver and bones.

Both groups were balanced with patients harbouring the most common tumour types for age, except castration-resistant prostate cancer (CRPC), which constituted 83 of 315 (26\%) cases in group B vs 49 of $689(7 \%)$ in group A. Both groups received balanced treatments; $65(9.4 \%)$ and $27(8.5 \%)$ received targeted agents in combination with chemotherapy in groups $\mathrm{A}$ and $\mathrm{B}$, respectively.

Phase I trials are largely only available in specialised centres, which may be a limiting factor for referring older patients; we therefore examined distance from home to treatment facility and its associations with outcomes in the older patients. We found that $67 \%, 21 \%$, and $12 \%$ patients travelled $<1,1-2$, and $>2 \mathrm{~h}$ to receive treatment in our hospital. Distance to home facility was however not found to be a factor associated with survival outcomes in our series (Supplementary Table 1).

Tolerability. Fifty-four (8.0\%) patients in group A required dose interruptions while on trial, compared with 25 (8.0\%) in group B $(\geqslant 65$ years). Dose reductions were observed in 34 (5.0\%) patients in group A vs $14(4.0 \%)$ patients in group B. Treatment was stopped in $41(6.0 \%)$ patients in group A, compared with $14(4.0 \%)$ patients in group $B$.
Table 2. Tolerability and toxicities:

\begin{tabular}{|c|c|c|c|}
\hline & $<65$ years & $>65$ years & $P$-value \\
\hline \multicolumn{4}{|c|}{ Dose interruptions (total) } \\
\hline None & $560(81)$ & $254(81)$ & 0.26 \\
\hline DI & $54(8)$ & $25(8)$ & \\
\hline DR & $34(5)$ & $22(7)$ & \\
\hline Treatment stopped & $41(6)$ & $14(4.0)$ & \\
\hline Unknown & $1(0.1)$ & $0(0)$ & \\
\hline
\end{tabular}

Grade III-V toxicities (highest toxicity per case is considered)

\begin{tabular}{|l|c|c|c|}
\hline & $0(0)$ & $2(0.6)$ & \\
Grade 3 & $118(17.1)$ & $55(17.5)$ & \\
Grade 4 & $38(5.5)$ & $19(6.0)$ & \\
Grade 5 & $1(0.2)$ & $2(0.6)$ & \\
Total & $157(22.8)$ & $78(24.8)$ & \multirow{2}{*}{0.52} \\
No grade III-V toxicity & $532(77.2)$ & $237(75.2)$ & \\
\hline
\end{tabular}

Abbreviations: $\mathrm{DI}=$ dose interruptions; $\mathrm{DR}=$ dose reductions; none $=$ when there was a toxicity but it did not lead to DI or DR. This table shows highest grade of intervention (treatment stopped, DR, or DI) with total number of trial entrants affected by age group.

Overall, grade $3-5$ toxicities were observed in $22.8 \%$ and $24.8 \%$ in Groups A and B, respectively. Three toxicity-related deaths were reported; two in group $B$ (owing to neutropenic sepsis in one patient and septicaemia in the other) and one in group A (owing to respiratory arrest). In group B, $9.5 \%$ and $15.6 \%$ of patients had un-planned hospital admissions and serious adverse events, respectively (data not shown). No statistically significant or clinically relevant difference was found between the two groups in frequency or occurrence of grade III/V toxicities (Table 2).

Efficacy data. Radiological RECIST antitumor responses were observed in both groups of patients; 35 (5.2\%) PR were observed in group A, whereas 2 CR $(0.6 \%)$ and $11(3.5 \%)$ PR was observed in group B ( $\geqslant 65$ years old). A total of $209(30.3 \%)$ patients in group A had RECIST SD, vs 147 (47.3\%) patients in group B. There were 410 (59.5\%) patients who had RECIST PD at first assessment, whereas this was observed in 111 (35.7\%) patients in group B.

A total of $105(15.2 \%)$ patients in group A were deemed to have gained clinical benefit at 6 months ( $C R, P R$, or $S D \geqslant 6$ months), 
Table 3. Efficacy estimates in patients

\begin{tabular}{|c|c|c|c|}
\hline & $\begin{array}{c}<65 \text { years } \\
n(\%)\end{array}$ & $\begin{array}{c}>65 \text { years } \\
n(\%)\end{array}$ & $P$-value \\
\hline \multicolumn{4}{|l|}{ Best response } \\
\hline $\begin{array}{l}\text { CR } \\
\text { PR } \\
\text { SD } \\
\text { PD } \\
\text { Unknown } \\
\text { Missing } \\
\text { Total }\end{array}$ & $\begin{array}{c}0(0) \\
35(5.2) \\
209(30.3) \\
410(59.5) \\
26(3.8) \\
9(1.3) \\
689\end{array}$ & $\begin{array}{c}2(0.64) \\
11(3.5) \\
147(47.3) \\
111(35.7) \\
40(12.9) \\
4(1.3) \\
315\end{array}$ & 0.025 \\
\hline \multicolumn{4}{|l|}{ CBR at 4 months } \\
\hline $\begin{array}{l}\text { No clinical benefit (SD }<4 \text { months }+ \text { PD) } \\
\text { Clinical benefit (CR }+P R+S D>4 \text { months) } \\
\text { Missing } \\
\text { Unknown } \\
\text { Total }\end{array}$ & $\begin{array}{r}505(73.3) \\
149(21.6) \\
9(1.3) \\
26(3.8) \\
689\end{array}$ & $\begin{array}{r}205(65.1) \\
65(20.6) \\
4(1.3) \\
40(12.9) \\
315\end{array}$ & 1.00 \\
\hline \multirow[b]{2}{*}{ PFS in months } & Median $(95 \% \mathrm{Cl})$ & Median $(95 \% \mathrm{Cl})$ & \multirow[b]{2}{*}{0.0001} \\
\hline & $1.87(1.72-2.02)$ & $3.55(2.96-4.14)$ & \\
\hline OS in months & $7.79(6.88-8.7)$ & $9.86(8.69-11.03)$ & 0.003 \\
\hline
\end{tabular}

compared with $45(14.3 \%)$ patients in Group B $(P=0.77)$. No clinical benefit at 6 months (RECIST SD $<6$ months or PD at first assessment) was observed in the majority of patients in both groups; 549 (79.7\%) patients in Group A vs 226 (71.8\%) patients in Group B. Similar CBR data were observed at 4 months (Table 2). The differences in CBR were not statistically significant between both groups.

The response rates (RR) (4.1\%), 1-year survival (42\%), PFS (3.5 months), and OS (9.9 months) in Group B compared favourably with those to Group A $(\mathrm{RR}=5.2 \%, 1$-year survival $=31 \%$, $\mathrm{PFS}=1.9$ months, and $\mathrm{OS}=7.8$ months) (Table 3 and Figures 1 and 2). Moreover 2-, 3-, and 5-year survivals were comparable between the two groups (Supplementary Table 2).

In order to exclude a statistical bias in results due to the imbalance in patients with CRPC, a second efficacy analysis was undertaken in patients with advanced CRPC removed. This analysis showed that when patients with CRPC were excluded from both groups, RR $(P=0.05) \mathrm{CBR}$ at 4 months $(P=0.73)$, and 6 months $(P=0.71)$ remained comparable between the two groups (Supplementary Tables $3 \mathrm{a}$ and $3 \mathrm{~b}$ ).

Prognostic biomarkers of PFS and OS and validation of RMH prognostic score. Different prognostic biomarkers were assessed using both univariate and multivariate analyses in group B. These results are summarised in Table 4 and Supplementary Table 4. Multiple factors were prognostic for worse OS in a univariate analysis, including ECOG PS, number of lines of chemotherapy, and $\mathrm{RMH}$ prognostic score, and these three factors remained prognostic in a multivariate analysis.

Validation of RMH prognostic score. Importantly, the RMH score remains a significant prognostic variable for OS in this population of older patients, with an estimated HR higher than previously observed at 2.58 (95\% CI 1.95-3.42). It was also significant for PFS with a HR of 1.7 (95\% CI 1.25-2.30). Multivariate models for OS and PFS were then built considering only candidate variables with $P<0.1$ on univariate analysis for

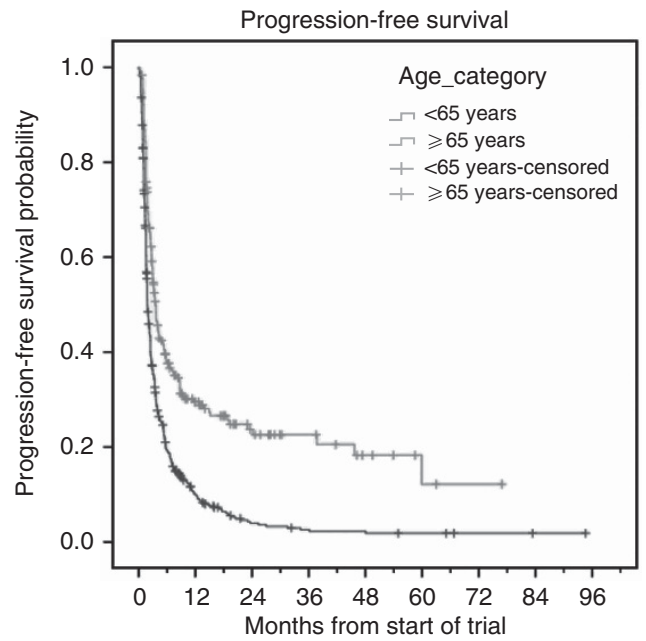

Figure 1. Progression-free survival plot. The median progression-free survival for our overall study population is 2.37 months (95\% Cl: 2.12 2.62 months). Patients who participated in more than one line of Phase I trial therapy are included in this analysis. Patients who die without progression are censored at the date of death. Patients alive without progression are censored at the date they were last known to be alive.

inclusion. All variables considered (RMH score, previous chemo, PS) remained prognostic for OS on multivariate analysis; whereas $\mathrm{RMH}$ score, previous chemo, and creatinine clearance remained prognostic for PFS on multivariate analysis.

\section{DISCUSSION}

To our knowledge, this is the largest comprehensive report on the clinical experience of older vs younger patients with advanced 


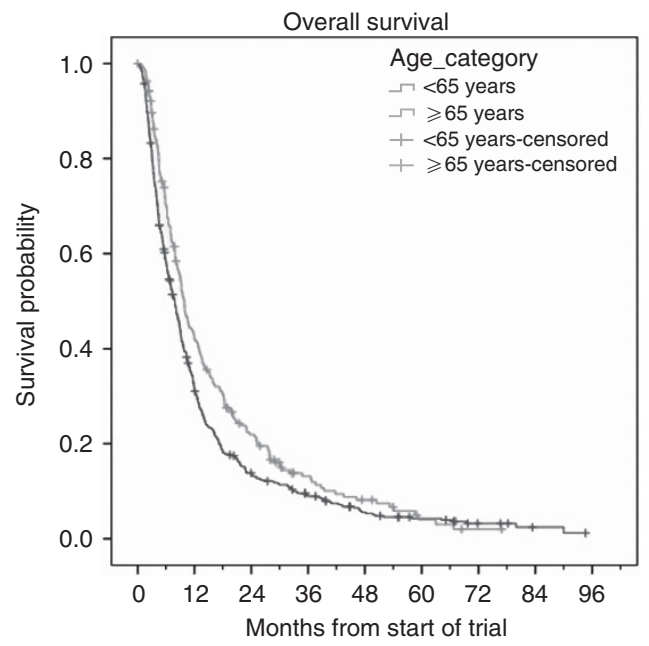

Figure 2. Overall survival plot. The median overall survival for our overall study population is 8.42 months (95\% Cl: 7.7-9.1 months). Patients alive without progression are censored at the date they were last known to be alive.

Table 4. Multivariate analysis (stepwise)-prognostic variables in older patients ( $>65$ years)

\begin{tabular}{|c|c|c|c|c|}
\hline & \multicolumn{2}{|l|}{ PFS } & \multicolumn{2}{|l|}{ OS } \\
\hline Variable & $\mathrm{HR}(95 \% \mathrm{Cl})$ & $P$-value & $\mathrm{HR}(95 \% \mathrm{Cl})$ & $P$-value \\
\hline \multicolumn{5}{|l|}{ ECOG PS } \\
\hline $\begin{array}{l}\text { Overall } \\
0 \\
1 \\
2\end{array}$ & & & $\begin{array}{c}1 \\
1.29(0.95-1.76) \\
2.27(1.19-4.34)\end{array}$ & $\begin{array}{l}0.033 \\
0.102 \\
0.013\end{array}$ \\
\hline \multicolumn{5}{|c|}{ Creatinine clearance (categorical -4 quartiles) } \\
\hline $\begin{array}{l}\text { Overall } \\
1 \\
2 \\
3 \\
4\end{array}$ & $\begin{array}{c}1 \\
1.05(0.65-1.69) \\
1.70(1.06-2.71) \\
0.87(0.52-1.46)\end{array}$ & $\begin{array}{l}0.024 \\
0.856 \\
0.028 \\
0.598\end{array}$ & & \\
\hline \multicolumn{5}{|c|}{ Number of chemo } \\
\hline $\begin{array}{l}\text { Overall } \\
0 \\
1 \\
2 \\
3 \\
4+\end{array}$ & $\begin{array}{l}1.85(1.13-3.03) \\
2.01(1.20-3.38) \\
1.92(1.07-3.46) \\
1.34(0.71-2.55)\end{array}$ & $\begin{array}{l}0.048 \\
0.014 \\
0.008 \\
0.029 \\
0.370\end{array}$ & $\begin{array}{l}2.27(1.51-3.40) \\
2.39(1.57-3.62) \\
3.20(2.00-5.14) \\
2.03(1.19-3.47)\end{array}$ & $\begin{array}{r}<0.001 \\
<0.001 \\
<0.001 \\
<0.001 \\
0.009\end{array}$ \\
\hline \multicolumn{5}{|c|}{ RMH score (grouped) } \\
\hline $\begin{array}{l}0-1 \\
2-3\end{array}$ & $\begin{array}{c}1 \\
1.60(1.13-2.26)\end{array}$ & 0.008 & $\begin{array}{c}1 \\
2.08(1.55-2.79)\end{array}$ & $<0.001$ \\
\hline $\begin{array}{l}\text { Abbreviation } \\
\text { Categorical } \\
\text { Group; OS }=\end{array}$ & $\begin{array}{l}\text { egorical }-<2 \& \\
\text { uartiles }=\text { albumin } \\
\text { Il survival; PFS = pr }\end{array}$ & netastat & $\begin{array}{l}\text { tes = number of me } \\
=\text { Eastern Cooperat } \\
\text { ival; } \mathrm{PS}=\text { performan }\end{array}$ & $\begin{array}{l}\text { static sites; } \\
\text { Oncology } \\
\text { status. }\end{array}$ \\
\hline
\end{tabular}

cancers treated on phase I trials. Importantly, we assess key factors in these patient populations, including efficacy, safety, and prognostic factors of each patient. We have demonstrated that older patients who enter Phase I clinical trials have similar safety and efficacy outcomes as their younger counterparts and should therefore be considered for such early-phase studies.

In general, clinical trials provide objective evidence to support the use of optimal treatments for a 'one size fits all' patient population. However, older patients $(\geqslant 65$ years old) are historically under-represented in such clinical trials (Scher and Hurria, 2012; Hurria et al, 2014) owing to multiple reasons, including restrictive inclusion criteria, concerns over tolerability and in certain cases, reluctance of patients, as well as their carers and clinicians to consider entry into experimental clinical trials.

Phase I clinical trials are traditionally considered as a means of establishing the maximum tolerated dose of anticancer therapies. However, with the advent of molecularly targeted therapeutics and mapping out of the underlying biology of different cancers and antitumor agents, they may now represent bona fide trial options that may be of benefit, subgroups of patients who have failed all standard available anticancer therapies irrespective of their age (Khan et al, 2014). The lack of representation of older patients with advanced cancers in clinical trials is widely reported (Hutchins et al, 1999; Talarico et al, 2004).

This current study is unique as it reports on $>1000$ consecutive patients treated in a large Phase I trials centre, thus minimising any selection bias and optimising the statistical power of this study. Two other similar studies on smaller patient numbers have been published on the assessment of patient outcomes in older patients treated on phase I trials (Zafar et al, 2011; Tai et al, 2015). The study by Zafar and colleagues involved 216 patients treated in a US centre and compared the outcomes of these enrolled patients to those who were not enrolled into clinical trials owing to trial ineligibility or the loss of follow-up. The study by Tai and colleagues involved 296 patients treated in Singapore and its conclusions on efficacy and toxicity comparing elderly and younger patients were similar to ours, that is, that no significant differences were seen despite greater co-morbidity in older patients.

By contrast, a recent study by Rowe et al (2014) concluded that older patients had higher likelihood of not completing phase I clinical trials compared with younger patients. This study however included small number of older patients $(n=69)$ with different cutoff for age (above or below 70 years) and included patients treated with wide range of phase I compounds including cytotoxics, immunotherapy, and targeted therapies $(33.3 \%$, $10.1 \%$, and $56.6 \%$, respectively, in older patients). Intriguingly, the rates of completion of 12 weeks of treatment in older and younger groups in this study were comparable $(32 \%$ vs $37 \%$, respectively, $P=0.59$ ); however, in patients who were unable to complete treatment, more patients in the older group were unable to complete owing to toxicities. In the present study, $>90 \%$ of patients in both groups were treated with targeted therapies which offers a plausible explanation as to why differences in tolerability were found between the two studies.

Efficacy, which is often a secondary end point of such phase I studies and an important means for understanding tumour biology, was actually found to be better in older patients. However, as many older patients with CRPC were treated during this time period on phase I trials with the CYP17 inhibitor abiraterone (which now has established efficacy), we reassessed these efficacy data by excluding such patients from the analysis and found that the efficacy remained comparable in the two groups.

Our group and others have previously reported on various prognostic models that may help to determine the outcomes of patients enrolled in to phase I trials (Han et al, 2003; Arkenau et al, 2008, 2009; Wheler et al, 2012). In our multivariate analysis, we found that serum albumin $<35 \mathrm{~g} \mathrm{dl}^{-1}, \mathrm{LDH}>192 \mathrm{Ul}^{-1}$ and the number of lines of previous chemotherapy were significantly associated with a worse OS. In addition, distance from home to the treatment facility was not found to be a factor associated with survival outcomes in our series. To our knowledge, these are the first data suggesting that distance to home facility should not deter physicians from referring suitable patients for phase I trials.

It is inevitable that our data represent a highly selected patient population; given the strict adherence to inclusion criteria for entry into Phase I trials. But once these criteria have been met, our data indicate that in Phase I trials the experience of patients aged over 65 years in terms of tolerability and efficacy will not differ 
substantially from younger patients. We conclude that Phase I clinical trials should be considered for advanced cancer patients regardless of age, following full discussion of the key issues of risk, benefit, and time commitment. Patient selection for such trials may be aided by the application of the RMH prognostic score.

\section{ACKNOWLEDGEMENTS}

The Drug Development Unit of the Royal Marsden NHS Foundation Trust and The Institute of Cancer Research is supported in part by a programme grant from Cancer Research UK Support was also provided by the Experimental Cancer Medicine Centre (to The Institute of Cancer Research) and the National Institute for Health Research Biomedical Research Centre (jointly to the Royal Marsden NHS Foundation Trust and The Institute of Cancer Research).

\section{CONFLICT OF INTEREST}

The authors declare no conflict of interest.

\section{REFERENCES}

Arkenau HT, Barriuso J, Olmos D, Ang JE, de Bono J, Judson I, Kaye S (2009) Prospective validation of a prognostic score to improve patient selection for oncology phase I trials. J Clin Oncol 27(16): 2692-2696.

Arkenau HT, Olmos D, Ang JE, de Bono J, Judson I, Kaye S (2008) Clinical outcome and prognostic factors for patients treated within the context of a phase I study: the Royal Marsden Hospital experience. Br J Cancer 98(6): 1029-1033.

Edwards BK, Howe HL, Ries LA, Thun MJ, Rosenberg HM, Yancik R, Wingo PA, Jemal A, Feigal EG (2002) Annual report to the nation on the status of cancer, 1973-1999, featuring implications of age and aging on U.S. cancer burden. Cancer 94(10): 2766-2792.

Han C, Braybrooke JP, Deplanque G, Taylor M, Mackintosh D, Kaur K, Samouri K, Ganesan TS, Harris AL, Talbot DC (2003) Comparison of prognostic factors in patients in phase I trials of cytotoxic drugs vs new noncytotoxic agents. Br J Cancer 89(7): 1166-1171.

Hurria A, Dale W, Mooney M, Rowland JH, Ballman KV, Cohen HJ, Muss HB, Schilsky RL, Ferrell B, Extermann M, Schmader KE, Mohile SG, CancerAging Research G (2014) Designing therapeutic clinical trials for older and frail adults with cancer: U13 conference recommendations. J Clin Oncol 32(24): 2587-2594.

Hutchins LF, Unger JM, Crowley JJ, Coltman Jr CA, Albain KS (1999) Underrepresentation of patients 65 years of age or older in cancer-treatment trials. N Engl J Med 341(27): 2061-2067.
Jemal A, Bray F, Center MM, Ferlay J, Ward E, Forman D (2011) Global cancer statistics. CA Cancer J Clin 61(2): 69-90.

Khan K, Ang JE, Starling N, Sclafani F, Shah K, Judson I, Molife LR, Banerji U, de Bono JS, Cunningham D, Kaye SB (2014) Phase I trials in patients with relapsed, advanced upper gastrointestinal carcinomas: experience in a specialist unit. Gastric Cancer 17(4): 621-629.

Paik PK, Rudin CM, Brown A, Rizvi NA, Takebe N, Travis W, James L, Ginsberg MS, Juergens R, Markus S, Tyson L, Subzwari S, Kris MG, Krug LM (2010) A phase I study of obatoclax mesylate, a Bcl-2 antagonist, plus topotecan in solid tumor malignancies. Cancer Chemother Pharmacol 66(6): 1079-1085.

Pal SK, Katheria V, Hurria A (2010) Evaluating the older patient with cancer: understanding frailty and the geriatric assessment. CA Cancer J Clin 60(2): 120-132.

Rowe J, Patel S, Mazo-Canola M, Parra A, Goros M, Michalek J, Kelly K, Weitman S, Karnad A (2014) An evaluation of elderly patients $(>/=70$ years old) enrolled in Phase I clinical trials at University of Texas Health Science Center at San Antonio-Cancer Therapy Research Center from 2009 to 2011. J Geriatr Oncol 5(1): 65-70.

Rubenstein LZ, Josephson KR, Nichol-Seamons M, Robbins AS (1986) Comprehensive health screening of well elderly adults: an analysis of a community program. J Gerontol 41(3): 342-352.

Scher KS, Hurria A (2012) Under-representation of older adults in cancer registration trials: known problem, little progress. J Clin Oncol 30(17): 2036-2038.

Tai WM, Lim C, Ahmad A, Ong WS, Choo SP, Lim WT, Tan EH, Kanesvaran R, Tan DS (2015) Do elderly patients benefit from enrollment into Phase I Trials? J Geriatr Oncol 6(3): 241-248.

Talarico L, Chen G, Pazdur R (2004) Enrollment of elderly patients in clinical trials for cancer drug registration: a 7-year experience by the US Food and Drug Administration. J Clin Oncol 22(22): 4626-4631.

Townsley CA, Chan KK, Pond GR, Marquez C, Siu LL, Straus SE (2006) Understanding the attitudes of the elderly towards enrolment into cancer clinical trials. BMC Cancer 6: 34

Wheler J, Tsimberidou AM, Hong D, Naing A, Falchook G, Piha-Paul S, Fu S, Moulder S, Stephen B, Wen S, Kurzrock R (2012) Survival of 1181 patients in a phase I clinic: the MD Anderson Clinical Center for targeted therapy experience. Clin Cancer Res 18(10): 2922-2929.

Yee KW, Pater JL, Pho L, Zee B, Siu LL (2003) Enrollment of older patients in cancer treatment trials in Canada: why is age a barrier? J Clin Oncol 21(8): 1618-1623.

Zafar SF, Heilbrun LK, Vishnu P, Jasti P, Venkatramanamoorthy R, Ding L, Lorusso PM, Heath EI (2011) Participation and survival of geriatric patients in Phase I clinical trials: the Karmanos Cancer Institute (KCI) experience. J Geriatr Oncol 2(1): 18-24.

This work is published under the standard license to publish agreement. After 12 months the work will become freely available and the license terms will switch to a Creative Commons AttributionNonCommercial-Share Alike 4.0 Unported License.

Supplementary Information accompanies this paper on British Journal of Cancer website (http://www.nature.com/bjc) 